\title{
A mãe sob suspeita: falando da saúde da criança em idade escolar*
}

\author{
MOTHERS UNDER SUSPICION: TALKING ABOUT SCHOOLAGE CHILDREN'S HEALTH
}

LA MADRE SOBRE SOSPECHA: HABLANDO DE LA SALUD DEL NIÑO EN LA EDAD ESCOLAR

\author{
Maria de Lourdes Olivi', Rosa Maria Godoy Serpa da Fonseca²
}

\section{RESUMO}

O estudo teve por objetivo explicar a assistência à saúde da criança em idade escolar à luz do materialismo histórico e dialético, incluindo gênero para a abordagem do social. Os resultados referentes às representações dos pesquisados (trabalhadores de saúde, professores e mães) revelaram que as concepções sobre o processo saúde-doença são altamente biologicistas apesar de, em menor escala, terem sido feitas referências às suas dimensões psíquica $\mathrm{e}$ social. A análise dos dados, à luz da teoria feminista, aponta que a subalternidade de gênero é a origem das concepções preconceituosas em relação às mães das crianças estudadas. Tais preconceitos foram constatados nos três loci estudados (serviço de saúde, escola e família).

\section{DESCRITORES}

Saúde escolar.

Criança.

Mãe.

Família.

Feminismo.

\section{ABSTRACT}

This study has as its objective to explain the assistance to the school age child's health under the light of historic and dialectic materialism, including gender for the social approach. The results regarding the interviewees' representations (health professionals, teachers and mothers) revealed that the conceptions about the health-illness process of school pupils are highly biologicist, even though there were - but in a much smaller scale - references to its psychic and social dimensions. The data analysis, according to the feminist theory, shows that the idea of gender inferiority is the origin of the biased conceptions regarding the mothers of the studied children. Such prejudices were observed in the three locations studied (heath service, school and family).

\section{RESUMEN}

El objetivo del estudio fue explicar, desde el punto de vista del materialismo histórico y dialéctico, incluyendo género para la visión del social, la asistencia a la salud del niño en edad escolar. Los resultados referentes a las representaciones de los investigados (trabajadores del área de la salud, profesores y madres), han revelado que las concepciones a respecto del proceso salud-enfermedad de los niños en edad escolar son altamente biologicistas aunque, en menor medida, hayan sido hechas referencias a las dimensiones psíquica y social. El análisis de los datos bajo la teoría feminista apuntó que la inferioridad de género es el origen de las concepciones prejuiciosas en relación con las madres de los niños estudiados, tales prejuicios fueron constatados en tres sitios estudiados (servicio de la salud, escuela y familia).

\footnotetext{
* Extraído da tese "A mãe sob suspeita: a situação da assistência à saúde do escolar na ótica dos envolvidos". Escola de Enfermagem da Universidade de São Paulo, 1996.

1 Professora Doutora do Departamento de Enfermagem da Universidade Federal de São Carlos. lourdesolivi@ yahoo.com.br

2 Professora Titular do Departamento de Enfermagem em Saúde Coletiva da Escola de Enfermagem da Universidade de São Paulo.
}

\section{KEYWORDS DESCRIPTORES}

School health.

Child.

Mothers.

Family.

Feminism.
Salud escolar.

Niños.

Madres.

Familia.

Feminismo. 


\section{APRESENTAÇÃO}

$\mathrm{O}$ artigo tem por referência uma tese de doutorado que discute as concepções de trabalhadores de saúde, professoras e mães referentes ao processo saúde-doença de crianças em idade escolar, atendidas em uma unidade básica de saúde de um bairro periférico da cidade de São Paulo. Seus resultados visavam subsidiar o ensino e a prática assistencial em saúde coletiva, no conjunto das atividades desenvolvidas num projeto de integração docente assistencial. Os dados empíricos foram obtidos em uma unidade municipal de saúde e duas escolas da Região de Pirituba-Perus, do Município de São Paulo.

\section{INTRODUÇÃO}

Até o final da Idade Média, a criança era socializada por adultos de uma determinada comunidade e não especificamente pelos seus pais. A preocupação com a saúde da criança em idade escolar se deu na Europa, a partir do século XVIII, com o surgimento de um movimento amplo de proteção à vida de crianças e adultos. A mudança do valor social atribuído à criança foi reflexo do valor econômico da vida, a partir da emergência de uma nova estrutura social e econômica nas sociedades européias - o capitalismo. Nesse contexto, a mãe passou a ser considerada o melhor instrumento pelo qual deveria ser operada a normalização da sociedade, passando a ter então, entre suas funções, a responsabilidade de cuidar da casa, do marido e das crianças. Isso foi tão marcante e bem sucedido que, até hoje, todo processo que visa socializar a criança (formação de atitudes, comportamento e concepções) tem a mãe como sua principal $\operatorname{protagonista}^{(1)}$.

No Brasil, a maior parte dos estudos sobre a saúde da criança em idade escolar está embutida nas questões sociais do século XX. Muitos desses estudos são relatos da prática em saúde escolar desenvolvidos no âmbito da escola e também dos serviços de saúde. À época, ainda não se questionava o papel da mãe, muito embora, na Europa, o papel da mulher começasse lentamente a se modificar em relação à infância, a partir do século XVII. Passaram a ser incutidos sentimentos novos nas relações entre os membros da família, admitindo que por não estarem preparadas para a vida, cabia aos pais a responsabilidade pela formação moral e espiritual dos filhos.

A importância do presente estudo está na possibilidade de repensar a atual estrutura da prestação de assistência na área da saúde, a partir das questões e das necessidades de saúde-doença detectadas em uma população específica de uma dada formação social, articulada ao perfil de recursos humanos disponíveis e utilizados para isto. Ele foi pensando diante das demandas impostas pelo Sistema Único de Saúde de reorientar a composição e a dinâmica da equipe de saúde responsável pela assistência à criança em idade escolar. De fato, uma observação sistematizada acerca dessa assistência revelou que os atendimentos eram de cunho caracteristicamente biologicista e individualizante não diferindo, em qualidade, da assistência prestada ao restante da clientela, exceto no que se referia ao recorte etário. Tal constatação serviu para nortear a investigação junto a trabalhadores da unidade de saúde.

Ocorre que, historicamente, também a escola desenvolve atividades de saúde das crianças ainda que seja apenas encaminhamento para unidade de saúde quando apresentam problemas. Na família, por sua vez, a principal responsável pelo cuidado à criança é a mãe ou quem a substitui, sendo a pessoa que problematiza a situação de saúde da criança e busca soluções para os problemas encontrados. Isto revela que a atenção à criança em idade escolar se materializa na confluência destes três loci - serviços de saúde, escola e família - sendo resultante de tal confluência. Assim, o estudo abrangeu profissionais de saúde, professoras e mães.

A questão norteadora do estudo foi: Qual é a concepção básica que norteia a atenção prestada à criança pelos seus responsáveis, sejam eles pertencentes ou não à área da saúde (profissionais de saúde, famílias e professores)?

Para elucidá-la foram propostos os seguintes objetivos:

1. Identificar as condições materiais de existência das crianças atendidas em uma unidade básica de saúde de um bairro da cidade de São Paulo, segundo a inserção social das famílias, aspectos estes relevantes para a compreensão da determinação social da saúde do escolar.

2. Captar e analisar as concepções sobre o processo saúdedoença e intervenção em saúde dos responsáveis pela saúde da criança em idade escolar (família, escola e serviços de saúde), à luz do materialismo histórico e dialético, incluindo gênero para a abordagem do social.

\section{REFERENCIAL TEÓRICO-METODOLÓGICO}

No Brasil, no final do século XIX e início do século XX, grandes eram as preocupações com a civilidade, com a organização da família, com leis, costumes, regras e convenções. O regime capitalista se instaurava no lugar do escravismo e a tentativa era a de imprimir no Brasil o modelo burguês como modelo ideal de família. Dependia da mulher o comportamento familiar desejado demandando dela um árduo trabalho para que o núcleo familiar funcionasse atendendo as expectativas de toda a sociedade ${ }^{(2)}$.

Daquela época até o século XVIII, as formas de cuidar da criança, bem como as concepções que as determinavam, 
eram bastante diferentes das atuais. A consolidação da família moderna, que ocorreu primeiramente na burguesia, aconteceu graças à destruição das formas comunitárias tradicionais, reorganizando-se em função das necessidades da ordem capitalista $^{(1)}$.

A criança foi transformada num dos mais preciosos bens. Sua morte passou a ser vivida como um drama que atinge não apenas a mãe, mas também o pai (...). A partir dessa época, a mulher passou a adotar os estímulos em favor da 'boa mãe' que doravante teria suas responsabilidades ampliadas. A nova mãe, que se sente responsável pela saúde do filho, não oculta sua ansiedade e pede mais conseIhos e ajuda ao médico ${ }^{(3)}$.

A educação da mulher era considerada importante, uma vez que era responsável pelo futuro homem, construtor da nação. Entretanto, essa ideologia não foi vivida pelas mães pobres no Brasil. Desde os finais do século XIX, devido ao determinismo biológico que inferiorizava os negros, já havia uma profunda descrença em qualquer política social de inclusão política e social das famílias pobres e particularmente de negros ${ }^{(3)}$.

Quanto às pesquisas em saúde, até a década de 80 do século XX, as investigações sobre a saúde escolar no Brasil haviam sido realizadas na área médica e segundo a visão funcionalista prevalente na época. Neste sentido, o véu do cientificismo dava continuidade à exclusão social das crianças pobres, uma vez que as diferenças étnico-culturais que embasam as diversas formas de organização familiar não eram consideradas. A dificuldade da pesquisa em saúde era de não conseguir explicar o porquê das condições de vida e saúde da grande maioria das populações dos países da América Latina. A partir da década de 70, esta dificuldade desencadeou um movimento nos meios acadêmicos visando à elaboração de teorias mais explicativas das causas da ocorrência das doenças. Tal movimento, fundamentado no referencial teórico-filosófico do materialismo histórico e dialético, se opôs à concepção idealista de mundo representada pelo positivismo na produção do saber na área da saúde tornando as décadas de 70 e 80 fecundas em estudos diagnósticos, analíticos e propositivos sobre as questões de saúde no Brasil. O materialismo histórico e dialético surgiu como uma enorme perspectiva de análise inspirando muitos desses estudos, cuja diversidade de propostas apresenta a cidadania como um elemento comum ${ }^{(4)}$.

Foi na década de 80 que surgiram os primeiros estudos sobre saúde do escolar embasados nesta nova visão. Dentre alguns feitos pela enfermagem, destaca-se o estudo ${ }^{(4)}$ que através de categorias do materialismo histórico e dialético fez uma análise critica sobre a inserção do enfermeiro na saúde escolar.

A opção pelo materialismo histórico e dialético como o referencial de análise do estudo foi justamente pelo seu caráter histórico, que estabelece a relação dos fenômenos com as transformações ocorridas no modo de produção em cada época histórica e o seu caráter dialético, que pressupõe que as transformações da sociedade se dão a partir da superação das contradições dialéticas que constituem condição de existência do processo social. No materialismo histórico, a função social da filosofia se transforma, tornando-se tanto instrumento explicativo como transformador da vida e da sociedade.

Enquanto o materialismo histórico representa o caminho teórico que aponta a dinâmica do real na sociedade, a dialética refere-se ao método de abordagem desse real. Esforça-se para entender o processo histórico em seu dinamismo, provisoriedade e transformação. Busca apreender a prática social empírica dos indivíduos em sociedade (nos grupos e classes sociais) e realiza a crítica das ideologias, isto é, do imbricamento do sujeito e do objeto, ambos históricos e comprometidos com os interesses e as lutas sociais do seu tempo ${ }^{(5)}$.

Ocorre que da maneira clássica como foi pensado, este referencial tornou-se insuficiente para analisar as questões que cercam os fenômenos componentes da vida das mulheres, entre eles a maternidade, razão pela qual há a necessidade de introduzir nele a perspectiva de gênero, categoria que se refere ao sexo socialmente construído ${ }^{(6)}$.

\section{PROCEDIMENTOS METODOLÓGICOS}

\section{Observação da realidade}

A observação sistematizada da atenção à saúde da criança no cenário de estudo revelou quais os profissionais que os atendimentos eram caracteristicamente biologicistas e individualizantes. Na escola, a observação revelou que a protagonista principal dos encaminhamentos para a busca de soluções para os problemas de saúde da criança era a professora que, igualmente adotava providências baseadas predominantemente na dimensão biológica do agravo.

\section{Coleta de dados}

Os discursos dos participantes foram coletados a partir das seguintes consígnias:

Para os trabalhadores de saúde: Descreva com o máximo de detalhes que você se lembrar uma situação de atendimento a uma criança em idade escolar (5 a 14 anos) que você tenha vivenciado nesta unidade e que, além de você, da criança e do responsável por ela, tenham participado outras pessoas, tais como enfermeira, assistente social, auxiliar de enfermagem, etc. Relate o que você pensa e sente sobre essa situação.

Para as professoras: Descreva com o máximo de detalhes que você se lembrar uma situação de atendimento de um aluno ou uma sua aluna num posto de saúde. O que você sente e pensa desta situação?

Para as mães: Conte para mim, com detalhes, o atendimento dado a seu filho ou filha, em uma das vezes que você o (a) levou ao posto de saúde. O que você sente e pensa dessa situação? 
Foram entrevistados pelo menos um trabalhador de cada categoria profissional que atuava na unidade básica de saúde (médicos, enfermeiras, assistentes sociais) o que correspondeu a pelo menos $40 \%$ do total que informou trabalhar com escolares e perfazendo um conjunto de seis profissionais. Compuseram também a população de estudo quatro professoras e sete mães, sendo que duas professoras eram tanto do ano atual, como de anos anteriores cursados pelas crianças e outras eram professoras de mais de uma criança participante do estudo. As entrevistas com as professoras e as mães foram realizadas em duas escolas: uma municipal onde estudavam as crianças menores de 7 anos e uma estadual onde estudavam as crianças maiores.

A entrevista foi a estratégia utilizada para obter informações a respeito da visão de mundo dos sujeitos sobre o objeto de estudo. A decisão de utilizar esta modalidade de coleta de dados ocorreu após terem sido constatadas diferenças tanto da abordagem da problemática de saúde da criança, quanto em relação às características de organização do trabalho. Foram realizadas a partir da concepção de que diferentes formas de organização do trabalho determinam diferentes concepções sobre o processo saúde-doença. Para Minayo,

\begin{abstract}
o que torna a entrevista instrumento privilegiado de coleta de informações (...) é a possibilidade da fala ser reveladora de condições estruturais, de sistemas de valores, normas e símbolos (sendo ela mesma um deles) e, ao mesmo tempo, ter a magia de transmitir, através de um porta voz, as representações de um grupo determinado em condições históricas, sócio - econômicas e culturais específicas ${ }^{(5)}$.
\end{abstract}

\section{ANÁLISE E TRATAMENTO DO MATERIAL OBTIDO NAS ENTREVISTAS: A DEPREENSÃO DOS TEMAS}

Os depoimentos foram submetidos à análise de discurso, com o objetivo de verificar quais as visões de mundo dos enunciadores das falas. Depois, de acordo com os procedimentos recomendados $^{(7)}$, foi feita a depreensão dos temas subjacentes às categorias empíricas. A depreensão do temas consiste na retirada dos textos dos temas baseados no encadeamento das figuras concretas que aparecem no texto (figurativo) e que dão sentido a um tema. Para facilitar a apresentação dos temas depreendidos dos depoimentos, eles foram expressos em frases. Depreendidos os temas, a seguir, foi realizada a classificação percorrendo-se o seguinte caminho: primeiro foi feita a reunião dos temas de cada participante por conjunto específico (de trabalhadores de saúde, mães e professores) e depois procedeu-se à identificação das categorias emergentes dos próprios temas. Isso possibilitou um segundo agrupamento, qual seja, a reunião dos temas dos diferentes participantes e conjuntos, segundo as categorias identificadas.

As categorias foram relativas a concepções sobre: 1) Saú-de escolar; 2) Processo saúde-doença; 3) Assistência à criança em idade escolar; 4) Tratamento a agravos de saúde;
5) Organização do serviço de saúde; 6) Organização da escola; 7) Segmentos da sociedade envolvidos na assistência à saúde do escolar; 8) Processo de trabalho; 9) Escolar. Na seqüência, foi feito um novo agrupamento das representações temáticas componentes das diferentes categorias, observando-se a homogeneidade dos dados, a exclusão mútua, a pertinência e a objetividade. Resultaram então duas categorias empíricas: Concepções sobre o processo saúdedoença; Concepções sobre intervenção na saúde escolar.

\section{RESULTADOS}

\section{Características das crianças e suas famílias}

Das sete mães entrevistadas, seis tinham idade em torno de 30 anos e uma de 50 anos. Esta mãe, aposentada cinco meses antes da pesquisa, citou como motivo da aposentadoria precoce poder cuidar melhor do filho (adotivo). Todas as mulheres moravam com seus maridos, à exceção de uma que morava com a avó da criança (sua sogra) e era a chefe da família. Esta mãe era a única que exercia trabalho remunerado rotineiro como diarista. Duas mães só realizavam trabalho remunerado eventualmente.

Quanto às crianças, duas freqüentavam o pré-primário (uma tinha 5 e a outra 7 anos). As demais, duas de 9 e três de 10 anos, freqüentavam uma escola estadual de I Grau, estando duas na $3^{\mathrm{a}}$ série, duas na $4^{\mathrm{a}}$ série e uma numa classe especial. Isto porque, durante três anos, essa criança havia freqüentado a $1^{\text {a }}$ serie desta escola, sem conseguir aprovação. Duas destas crianças eram adotadas.

\section{Algumas características de vida e trabalho das familias}

Os chefes de família eram, na sua totalidade, agentes sociais não proprietários dos meios de produção, vendiam sua força de trabalho a outros, possuíam baixa qualificação profissional. Um deles estava desempregado há 8 meses e uma outra (avó da criança) apesar de aposentada há 8 anos, trabalhava como costureira autônoma. A variabilidade dos rendimentos dos chefes de família, (seis esposos e uma avó) era de zero a oito salários mínimos. Em três famílias, o rendimento dos chefes era acrescido pelos rendimentos das mulheres. A escolaridade dos chefes variava de quatro a 12 anos de estudo.

As famílias residiam em habitações unifamiliares de um a quatro cômodos, apenas uma em casa própria. Assim, eram famílias desprivilegiadas socialmente e com baixo poder aquisitivo, caracteristicamente das chamadas classes populares, conforme pesquisa realizada ${ }^{(8)}$. Todas utilizavam os serviços públicos de saúde da região.

\section{Concepções sobre saúde-doença}

O estudo mostrou que nos três loci estudados (unidade de saúde, família e escola) existia homogeneidade nas concepções sobre o processo de saúde-doença. Podem ser pon- 
tuadas pequenas diferenças nestes resultados predominando, porém, o viés biologicista, apesar das referências às dimensões psíquica e social, esta última, em muito menor escala.

\section{Concepções dos profissionais de saúde}

Nas concepções dos profissionais puderam ser identificadas tanto a teoria da unicausalidade como da multicausalidade e, com muito pouca expressão, a da determinação social do processo saúde-doença ${ }^{(8)}$.

Na teoria da unicausalidade, a doença é considerada apenas como resultado da ação de um agente biológico externo no organismo, evidenciando uma concepção unicausal e ontológica. No estudo, foi identificada uma visão simplista da doença o que levava à proposição de um único método para a solução do problema. Mesmo no caso das ações preventivas, em geral, eram únicas como se isso fosse suficiente para impedir o aparecimento do agravo à saúde. De uma maneira geral, esta concepção desconsidera as dimensões psíquica e social. Reconhece que a causa única e fundamental da doença situa-se fora do organismo humano acometido. Esteve presente e foi a concepção dominante desde o início das sociedades ocidentais, quando o ser humano não dispunha de meios para controlar a natureza. As causas das doenças eram atribuídas a fatores externos, geralmente de explicação metafísica, entrando ou saindo do corpo humano por forças sobrenaturais, sem qualquer controle. Ainda hoje são encontradas evidências de que esta concepção está bastante presente embora com roupagens diferentes das originais. As frases a seguir ilustram os achados:

- O profissional (ginecologista) considera que a questão da gravidez está relacionada à falta de formação da mãe sobre ovulação e sobre métodos contraceptivos.

- A profissional (ginecologista) avalia que apesar do perigo da AIDS a freqüência do uso da camisinha é muito baixa.

- A profissional (enfermeira) dá orientação sexual voltada para o uso da camisinha na prevenção da AIDS para os meninos.

- A profissional (atendente de enfermagem) considera que as doenças vêm do contato com outras crianças e da possibilidade de queda.

No que tange à multicausalidade, a causa da doença não é única, mas no seu aparecimento coexistem várias causas ou vários fatores causais que, por sua vez, agem como somatória de causas, sem que sejam atribuídos pesos a cada um deles. Desta forma, a sociedade e a organização social também constituem fatores causais, tanto quanto a constituição biológica do homem. Uma variante deste modelo é o Modelo da Tríade Ecológica segundo o qual as causas se ordenam dentro de três conjuntos possíveis de fatores que intervêm no aparecimento da doença relacionados ao agente (causador da doença), ao hospedeiro (homem) e ao meio ambiente (físico e social). O comportamento anormal de um destes conjuntos de fatores pode ocasionar o desequilíbrio do sistema e conseqüentemente o aparecimento da doença. Assim, a presença de um ambiente desfavorável ocasiona transtornos no hospedeiro e ativação do agente que até então pode ter permanecido inativo ou em estado de não agressão, rompendo o equilíbrio. O perfil epidemiológico constitui o conjunto das causas de doenças ou de mortes na população ${ }^{(8)}$.

Nesta pesquisa, as frases e temas extraídos dos depoimentos das trabalhadoras da equipe de saúde mental evidenciaram que a concepção predominante era a da multicausalidade, conforme segue:

- A profissional (psicóloga) relaciona os problemas de comportamento do menino aos problemas da mãe adotiva às dificuldades sociais, à escola e ao ambiente maior da criança.

- A profissional (fonoaudióloga) associa as alterações da fala (a queixa principal da criança) ao comportamento da criança, à sua história de vida, à mãe, a fatores orgânicos, ambientais e emocionais.

- A profissional (fonoaudióloga) considera que para compreender os problemas de linguagem, o profissional deve compreender o desenvolvimento psíquico, afetivo e motor da criança, sem conceitos rígidos de normalidade.

Chama a atenção o fato das frases anteriores revelarem que a mãe é a responsável pela doença da criança. Por ter aparecido mais fortemente nas concepções das professoras, este tema será tratado adiante.

Quanto ao social como determinante do processo saúde-doença, concepção que resvala na Teoria da Determinação Social do Processo Saúde-doença apareceu somente no depoimento da fisioterapeuta, embora de maneira frágil e superficial.

- A profissional (fisioterapeuta) considera esses problemas que alteram de forma global a criança como conseqüência da estrutura social dos clientes que vêm ao posto.

Das teorias explicativas do processo saúde-doença, essa é a que relaciona a causa última do comportamento do processo saúde doença à forma como a sociedade se organiza para a construção da vida social. Os fenômenos saúde e doença constituem expressões de um mesmo processo, evidenciando o seu duplo caráter: o biológico e o social, uma vez que encara que a natureza humana, apesar de ter um lastro biológico, se determina a partir da vida do homem em sociedade. Assim, a organização social passa a ser o determinante fundamental das manifestações deste processo e evidencia-se como uma forma de manifestação da qualidade de vida dos agentes sociais. Esta, por sua vez, é determinada pelos processos de produção e reprodução da vida social (trabalho e formas de vida). Do ponto de vista político, é a explicação mais 
comprometida com a organização social sendo, por isto, reveladora das contradições existentes entre as condições de vida e a inserção social dos indivíduos, famílias e grupos sociais ${ }^{(8)}$. Nenhuma destas articulações foi feita por qualquer integrante da pesquisa.

\section{Concepções das professoras}

A análise das falas das professoras revelou concepções embasadas na visão da classe dominante, portanto, ideológicas e, como tal, preconceituosas e discriminatórias, referendando que as diferenças de classe se traduzem em diferenças de olhares sobre os fenômenos sociais. Para elas, em última instância é a família a grande responsável pelas dificuldades das crianças, em especial as dificuldades impostas pelo processo saúde-doença.

- A professora detectou na criança problemas de expressão, de comportamento agressivo, relacionando-os com problemas familiares.

- A professora observou comportamento agressivo na mãe da criança e o relaciona com seus problemas de saúde e familiares.

A primeira frase/tema acima, comum entre as professoras, ilustra não só suas representações sobre o processo saúde-doença das crianças como também sobre os tipos de dificuldades identificados por elas, ou seja, as manifestações de ordem psíquica e social. A causa da doença aparece centrada no micro-ambiente familiar, sem qualquer articulação com os elementos macro-estruturais que constituem os determinantes dos problemas existentes na micro-estrutura familiar. A doença aparece como um desvio comportamental e social da criança, resultante dos desvios comportamentais da família (mãe), conforme a visão funcionalista descrita:

descrever a doença, como ela funciona e aparece em forma de fenômeno observável, desconhecendo as condições de sua produção, reduz a doença à noção de 'desvio' colocando-a no âmbito exclusivo do paciente ${ }^{(9)}$.

Aos olhos da professora, nem sempre a relação dos pais com a criança é uma relação positiva ou adequada. A frase/ tema que confirma essa observação é a seguinte:

- Para a professora, a maneira dos pais se relacionarem com a criança provoca regressão no seu comportamento.

As explicações dadas para os fenômenos são, na verdade, expressões do senso comum, centrado no paradigma dominante e, como tal, carregadas de juízo de valor em relação aos menos socialmente menos favorecidos, dentre eles, em especial a mãe, em cuja figura centra-se tudo o que é chamado de família.

\section{Concepções das mães}

De um modo geral, o contato com os trabalhadores de saúde permite às mães alguma forma de aprendizado. Assim, elas passam a enxergar a relação que se estabelece entre os diferentes problemas apresentados pelos filhos. Por conta disso, passam a ter uma concepção de saúde doença que incluem mais de uma dimensão, conforme a frase/tema:

- O problema do filho é expressão (troca de palavras) e de comportamento (vergonhoso) que está associado a um problema de formação da arcada dentária.

Além disso, pela proximidade com a meta-linguagem utilizada pelos profissionais de saúde, as mães repetem termos que identificam mesclas de concepções, ora relacionando o processo saúde-doença a vários fatores, ora a uma única causa sem, no entanto, revelar consistência em relação a isso.

\section{CONCEPÇÕES ACERCA DA INTERVENÇÃO NA SAÚDE DO ESCOLAR}

\section{Concepções dos trabalhadores de saúde}

Para os trabalhadores de saúde, a mãe deve participar no tratamento da criança e ao mesmo tempo também deve ser tratada, revelando uma concepção que se vincula à visão psicanalítica.

- A profissional (fono) entende o trabalho profissional com a criança como um processo, em conjunto com outro profissional (psicóloga) e que se estende ao atendimento psicológico da mãe.

Muitas das concepções da época freudiana são ainda hoje observadas.

\begin{abstract}
Muitos psicanalistas sugerem hoje às mães, cujos filhos têm problemas, que se submetam elas mesmas a um tratamento analítico. A idéia essencial é a de que não basta tratar a criança, senão se combate ao mesmo tempo, a raiz do mal, isto é, a má condição da mãe ${ }^{(3)}$.
\end{abstract}

$\mathrm{O}$ atendimento da criança com dificuldade escolar passa primeiro pela senda dos pais e visa esclarecer o sentido da relação materna (...)

especialmente nos casos em que filhos e pais formam ainda um só corpo (...) ao receber a mensagem dos pais não se está fazendo a psicoterapia deles ${ }^{(10)}$.

A psicoterapia precisa ser feita antes de encaminhar a criança para programas ou classes de reeducação, pois a inteligência não é um fator puramente quantitativo e tampouco equivale a uma adaptação.

\section{A inteligência é uma noção grosseira oposta artificialmen- te a afetividade. A debilidade nada tem haver com a estu- pidez, que é antes, defesa neurótica(10).}

Tal concepção revela, na verdade, uma responsabilização da família (mãe) em relação ao processo saúde-doença da criança, pois ao pretender tratá-la, o que está dizendo é que são os desequilíbrios e as ditas anormalidades comporta- 
mentais familiares as grandes causas do aparecimento dos problemas das crianças, sem relacioná-los a outra dimensão da realidade que não a singular, a relativa aos indivíduos ou pequenos grupos sociais. Nesta visão também se constata uma grande carga de preconceito em relação às mulheresmães, sobre as quais recai toda ordem de responsabilização da problemática da criança.

\section{Concepções das professoras}

A frase/tema a seguir mostra como as professoras também intervêm no comportamento da criança através da responsabilização da mãe ou mesmo transferindo a ela tal responsabilização.

- O comportamento agressivo da criança levou a professora a ter contato com a mãe.

As concepções das professoras e suas atitudes pedagógicas são embasadas na psicologia e na biologia e nem sempre elas percebem que o processo de desenvolvimento do individuo se inscreve num processo histórico-social que o determina e, por sua vez é por ele determinado. Como não percebem isso, continuam tentando fazer com que todas as crianças tenham sempre o mesmo padrão de comportamento formado pelos comportamentos idealizados das classes dominantes.

\section{Concepções das mães}

Conforme ocorreu em relação ao processo saúde-doença, no que tange à assistência, as mães em geral repetem o que ouvem dos profissionais de saúde, no entanto, de maneira desagregada e estereotipada, nem sempre condizente com o que efetivamente elas acreditam com base no saber popular mais tradicional. Ao repetir o discurso médico, elas revelam ao mesmo tempo, conhecimento e desconhecimento a respeito do agravo que acomete os filhos.

- A mãe identifica no filho problemas de expressão e de ser muito agitado.

- A mãe acha que o filho deveria ficar mais tempo com a psicóloga para saber brincar.

- O problema do filho é expressão (troca de palavras) de comportamento (vergonhoso) que está associado a um problema de formação da arcada dentária.

\section{DISCUSSÃO E ANÁLISE DOS RESULTADOS}

A análise dos resultados revela que em relação à assistência ao escolar pouca coisa mudou nos serviços de saúde após a aprovação da Lei do SUS ${ }^{(11)}$. Em relação ao processo saúde-doença, podem ser pontuadas apenas pequenas diferenças nas concepções dos profissionais, predominando, porém, o viés biologicista, mesmo diante de referências às dimensões psíquica e social, esta última, em muito menor escala.
O grande achado dessa pesquisa reside na identificação da mãe como responsável pelos problemas da criança, assim como é pela sua solução. A gênese disso situa-se no momento histórico em que a mãe passou a ser considerada o alvo privilegiado das ações educativas, prescritas pela ideologia dominante. Por isso, a partir daí, ela vem sendo o alvo principal das práticas de saúde dirigidas às crianças.

Neste estudo, está presente e é bastante evidente a ideologia dominante de cunho positivista, que proclama que a responsabilidade pela criança, inclusive pela sua saúde, cabe à família. Dentro desta, a grande responsável pela saúde dos filhos é a mãe, revelando uma concepção conservadora dos papéis femininos. A grande cuidadora é a mãe, correspondendo a isto a figura do pai provedor, contraditoriamente mesmo na ausência da figura paterna. Desta maneira, é de se esperar que seja também a responsável pela busca e garantia de assistência para os problemas dos filhos, num processo que inicia com a identificação do problema de saúde, geralmente, pelas professoras que solicitam às mães a obtenção do atendimento à saúde. Em seguida, o problema é confirmado pelos trabalhadores de saúde que para a sua solução exigem a participação da família. No entanto, a figura familiar que é chamada para isto é precisamente a mãe que, em geral, fica com a responsabilidade de solucionar o problema apresentado pela criança, com ou sem a ajuda de alguma outra instituição de saúde, quando existe tal encaminhamento. Em última instância, é sobre a mãe que recai o ônus que seria da família e, por que não dizer, de toda a sociedade.

Além disso, as características que revestem as responsabilidades atribuídas à mãe são:

1. Além da falta de autonomia para decidirem sobre a forma e conteúdo do cuidados/assistência às crianças, as mães não contam com nenhum respaldo para os atendimentos de saúde solicitados (pelas escolas ou pelos próprios serviços de saúde) para seus filhos.

2. As mães são severamente criticadas por não saberem discernir sobre a necessidade de atendimento ou não. Em vários depoimentos, especialmente dos médicos, foi possível identificar que os profissionais responsabilizam as mães pela procura considerada desnecessária da consulta médica, pela ocorrência da gravidez na adolescência, infecções vulvo-vaginais, alimentação incorreta, impossibilidade de recuperação da visão, atraso na vacinação e outras intercorrências. Todas as falhas foram relacionadas à falta de conhecimento das mães sobre os agravos à saúde das crianças.

3. São atribuídas às mães as falhas do tratamento principalmente quando não manifestam atitudes ou comportamentos considerados adequados à saúde dos filhos.

À semelhança dos médicos e das trabalhadoras de enfermagem, as trabalhadoras da equipe de saúde mental e as 
professoras também consideram que os problemas de saúde das crianças estão relacionados com os problemas econômicos e sociais das famílias, porém são à saúde e ao comportamento das mães que associam os problemas das crianças.

Outro aspecto diz respeito à mudança de foco em relação às causas das dificuldades de aprendizagem das crianças que na década de 80 eram atribuídas à dimensão fisiopatológica. Por isso, os problemas eram centralizados na própria criança e a desnutrição era apontada como a principal causa do baixo rendimento escolar. Atualmente, já se concebe que os problemas que afetam a aprendizagem podem ser de natureza biológica e social. Porém, como as concepções do social, em geral, limitam-se ao micro ambiente em que vive a criança, o que se observa é um deslocamento da causação biológica para a causação materna.

\section{A MÃE SOB SUSPEITA: A CULPABILIZAÇÃO DA MÃE SOBRE A SAÚDE DO FILHO}

A compreensão do fato da mãe aparecer nos discursos de todos os trabalhadores de saúde e das professoras como a pessoa mais implicada nos problemas de saúde da criança inicia-se pela análise dos seus determinantes, por meio de um olhar histórico sobre o pensamento dominante nas diferentes épocas, no que toca às responsabilidades das mulheres (mães) pelo cuidado dos filhos. Segundo a teoria feminista, a subalternidade de gênero ocorre em todas as classes sociais e pode ser considerada a origem das concepções preconceituosas em relação às mães das crianças estudadas. Na verdade,

há um tipo de supremacia e dominação masculina presente em todas as relações sociais, responsável pela exclusão sistemática das mulheres de todas as instâncias de poder e pela permanente desvalorização dos papéis e tarefas a ela atribuídos ${ }^{(12)}$.

Tal desvalorização seria exemplificada pela contribuição invisível, não remunerada, do trabalho doméstico das mulheres no custo de reprodução da força de trabalho.

A opressão da mulher tem suas causas na combinação entre as desigualdades geradas pelo sistema capitalista e as diferenças sociais entre os sexos construídas pelo patriarcado. Tal opressão tem sua origem na norma oficial que ditava que a mulher devia ser resguardada em casa, se ocupando dos afazeres domésticos, enquanto os homens asseguravam o sustento da família trabalhando no espaço da rua ${ }^{(13)}$.

No entanto, esta norma estava longe de retratar a realidade das mulheres pobres. Tratava-se, na realidade, de um estereótipo calcado nos valores da elite colonial, muitas vezes espelhado nos relatos de viajantes europeus, que servia como instrumento ideológico para marcar a distinção entre as mulheres burguesas e as mulheres pobres. Isto porque para as últimas, que procuravam possibilidade de sobrevivência como mantenedoras da família, a liberdade de circulação era imprescindível e desta forma ficava bastante complicado adaptaremse aos moldes de comportamento esperado, muito embora aspirassem, à semelhança de outras mulheres, ao casamento formal. Esta aspiração originava-se na fantasia que do casamento derivaria a felicidade, boa vida, a boa reputação e o respeito da sociedade. De uma maneira geral, as mulheres eram vistas como seres incompletos necessitando da figura masculina para se completarem ${ }^{(14)}$.

Derivado disto, a dominação masculina e a submissão feminina eram compreendidas no binômio obediência-amor.

\begin{abstract}
As mulheres obedeciam porque eram delicadas e meigas e ser mãe era o papel mais sublime que uma mulher poderia desejar. Assim, os papéis familiares de filha e esposa eram uma espécie de preparação para a função de mãe. A própria biologia apoiava as intenções de reorganização social colocando para o homem a força, a autoridade e a racionalidade e, para a mulher, a fragilidade, a submissão, o sentimento e, claro a vocação-mor para a maternidade ${ }^{(15)}$.
\end{abstract}

De lá para cá, muito embora se verifiquem mudanças no comportamento da sociedade em relação às mulheres impelindo-as cada vez mais para o mercado de trabalho em busca de melhores condições de vida ou mesmo de condições básicas de sobrevivência, ainda são muito fortes os apelos para que sejam elas as responsáveis pelo cuidado do grupo familiar e nele, das crianças. Longe de livrar-se ou de dividir o trabalho doméstico e o cuidado das crianças com os homens, quando foram para o mercado de trabalho as mulheres continuaram responsáveis por parte senão que pela totalidade desse cuidado. Isto se agrava quando da dissolução do grupo familiar, situação em que em geral os filhos permanecem com as mães constituindo outro modelo de família que não a nuclear anterior sobre a qual também recaem preconceitos e discriminações, pois que fogem ao padrão da família nuclear, cuja figura central, em termos de poder, é representada pelo homem. Assim, a construção da identidade feminina e a maternidade se unem de tal forma que possivelmente a primeira tem fundamental apoio na segunda, o que leva a pensar que se, sob certos aspectos, a maternidade agrega responsabilidades e significados que vão além da reprodução biológica, no sentido da reprodução social.

Diferente do que ocorria até a primeira metade do século passado, hoje, a opção pela maternidade é fato usualmente aceito.

\footnotetext{
A escolha da maternidade é um fenômeno moderno, consolidado no decorrer do século XX com o avanço da industrialização e da urbanização. As transformações pelas quais os padrões de maternidade vêm passando nos últimos trinta anos devem ser pensadas em conexão com estes processos sociais e com a globalização econômica, que contribuiu para acelerar a difusão de novos padrões de comportamento e consumo, incluindo-se aí as novas tecnologias reprodutivas ${ }^{(16)}$.
} 
No entanto, persistem dúvidas sobre a forma e a qualidade dessa opção.

Em relação aos fatores sociais (relacionados à escolha da maternidade) estão as condições econômicas e culturais das famílias; os projetos e as possibilidades profissionais das mulheres. As facilidades e as dificuldades variam de uma classe para outra e de país para país; a situação e a qualidade dos serviços públicos e/ou particulares disponíveis; o apoio ou a proximidade da família extensiva; as redes de solidariedade femininas. Entretanto, as condições materiais não determinam, via de regra, a escolha da maternidade, embora definam suas características e possibilidades ${ }^{(16)}$.

\section{REFERÊNCIAS}

1. Miranda MG. O processo de socialização na escola: a evolução da condição social da criança. In: Lane STM, organizadora. Psicologia social: o homem em movimento. São Paulo: Brasiliense; 1984. p. $125-35$.

2. Soihet R. Mulheres pobres e violência no Brasil urbano. In: Bassanezi C, coordenador. História das mulheres no Brasil. São Paulo: Contexto; 1997. p. 362-400.

3. Badinter E. Um amor conquistado: o mito do amor materno. Trad. de Waltensir Dutra. Rio de Janeiro: Nova Fronteira; 1985.

4. Ferriani MGC. A inserção do enfermeiro na saúde escolar. São Paulo: EDUSP; 1991.

5. Minayo MCS. O desafio do conhecimento: pesquisa qualitativa em saúde. São Paulo: Hucitec; 1992.

6. Fonseca RMGS. Mulher, reprodução biológica e classe social: a compreensão do nexo coesivo através do estudo dialético do perfil reprodutivo de mulheres atendidas nas Unidades Básicas de Saúde [tese]. São Paulo: Escola de Enfermagem, Universidade de São Paulo; 1990.

7. Fiorin JL. Linguagem e ideologia. São Paulo: Ática; 1988.

8. Ferreira MCT, Marturano EM. Ambiente familiar e os problemas de comportamento apresentados por crianças com baixo desempenho Escolar. Psicol Reflex Crit. 2002; 15(1):67-89.
Apesar do exposto, o presente estudo revelou que para a sociedade a função social da maternidade abrange não só a reprodução dos corpos, mas a esponsabilização sobre eles. imputando sobre as mulheres o ônus de colocar no mundo, manter e cuidar dos filhos, fazendo parte deste ônus tomar parte (importante) nas funções que seriam responsabilidade de outras instâncias do social como o próprio genitor, a escola e o sistema de saúde. Ainda, como parte deste ônus, paira sobre as mulheres a culpa dos problemas dos filhos, dado que acabam sendo as maiores responsáveis por eles.

9. Garcia JC. Medicina e sociedade: as correntes de pensamento no campo da saúde. In: Nunes ED, organizador. Medicina social: aspectos históricos e teóricos. São Paulo: Global; 1983. p. 95-132.

10. Mannoni M. A criança retardada e a mãe. $4^{\mathrm{a}}$ ed. São Paulo: Martins Fontes; 1995.

11. Brasil. Lei n. 8080, de 19 de setembro de 1990. Dispões sobre as condições para promoção, proteção e recuperação da saúde, a organização e o funcionamento dos serviços correspondentes e dá outras providências. Diário Oficial da União, Brasília, 20 set. 1990. Seção 1, p. 18055.

12. Goldberg A. Tudo começou antes de 1975: idéias inspiradas pelo estudo da gestação de um feminismo "bom para o Brasil". In: Núcleo de Estudos da Mulher e Relações Sociais de Gênero (NEMGE). Relações de sexo x relações de gênero. São Paulo: NEMGE; 1989. p. 1-45.

13. Fonseca RMGS. Eqüidade de gênero e saúde das mulheres. Rev Esc Enferm USP. 2005; 39(4):450-9.

14. Fonseca C. Ser mulher, mãe e pobre. In: Bassanezi C, coordenador. História das mulheres no Brasil. São Paulo: Contexto; 1997. p. 510-53.

15. Pedro JM. Mulheres do Sul. In: Bassanezi C, coordenador. História das mulheres no Brasil. São Paulo: Contexto; 1997. p. 278-321.

16. Scavone L. Dar a vida e cuidar da vida: feminismo e ciências sociais. São Paulo: Ed. UNESP; 2004. 